\title{
Sustaining U.S. Competitiveness in Semiconductor Manufacturing
}

Priorities for CHIPS Act Incentives

CSET Policy Brief

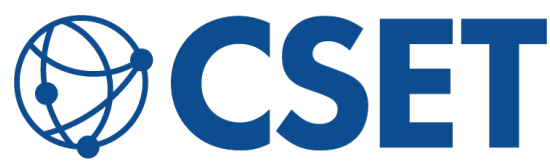

\author{
AUTHOR
}

Will Hunt

CENTER for SECURITY and EMERGING TECHNOLOGY 


\section{Executive Summary}

The American semiconductor manufacturing industry needs a course correction. The ongoing global chip shortage has shown that U.S. economic and national security depend on secure access to computer chips. But since 1990, the U.S. share of global semiconductor manufacturing capacity has declined while the shares of South Korea, Taiwan, and China have increased. To reverse this trend, Congress passed the CHIPS for America Act, which became law at the start of 2021, authorizing the Department of Commerce to administer tens of billions of dollars in federal grants with the aim of incentivizing chipmakers to increase their manufacturing capacity in the United States. ${ }^{1}$

CHIPS Act incentives will help sustain the United States' advantages as a leader in semiconductor manufacturing. The United States has many features that are appealing to chipmakers, including top talent; the world's best chip design firms; excellent intellectual property protection; and ample land for developing semiconductor fabrication facilities, known as fabs. U.S. and foreign chipmakers alike have expressed interest in establishing leading-edge chipmaking capacity in the United States with the help of federal incentives. And because of the high economies of scale involved in advanced chipmaking, these initial investments could translate into long-term commitments, helping keep the United States at the leading edge of semiconductor manufacturing for the foreseeable future.

But to be effective, CHIPS Act incentives must be carefully targeted toward specific types of semiconductor capacity. This report therefore assesses (1) the types of chip capacity that are in most urgent need of reshoring from a national security perspective; (2) how much capacity can and should be built for these types of chips with available incentives; and (3) how incentives should be distributed across different types of chips. Note that it is beyond the scope of this report to assess priorities for the $\$ 2$ billion set aside for mature technology nodes in the U.S. Innovation and Competition Act. This funding should likely go toward the most sensitive needs of the U.S. government, such as specialized analog chips used in military technologies. This report focuses instead on 
how to spend the remaining $\$ 37$ billion in manufacturing incentives.

\section{Findings:}

- Overdependence on the supply of leading-edge and (to a lesser degree) legacy logic chips manufactured in China and Taiwan threatens U.S. economic and national security.

- U.S. consumption of logic is worth tens of billions of dollars per year, and an important minority $(25$ percent) of U.S. logic consumption goes toward more sensitive applications including artificial intelligence, data centers, and the military, as well as automotive applications (including military vehicles).

- Roughly 85 percent of global leading-edge 5 nanometers $(\mathrm{nm})$ logic manufacturing capacity is located in Taiwan, and roughly 65 percent of global legacy (>16 nm) logic capacity is located in China and Taiwan. In the event of a conflict with China over Taiwan, the United States would likely lose access to all of this capacity.

- The United States has zero onshore leading-edge (5 $\mathrm{nm})$ logic capacity, and 8 percent of global legacy logic capacity above the $16 \mathrm{~nm}$ node.

- Overdependence on the supply of dynamic random access memory (DRAM) chips manufactured in South Korea also poses risks.

- DRAM chips are also economically vital to the United States, but the country has minimal onshore DRAM manufacturing capacity and none at the leading edge.

- Half of global DRAM capacity is in South Korea, and most of the remainder (43 percent) is in Taiwan and China. South Korea faces moderate risks of disruptions in manufacturing due to its proximity to North Korea. 
- Other types of lower-priority semiconductor devices-flash memory, analog, optoelectronics, sensors, and discretespose lower risks of major disruptions.

- The production of these devices is less concentrated in South Korea, Taiwan, and China; and most of these devices are commoditized and substitutable in the event of interruptions in supply. ${ }^{2}$

\section{Recommendations:}

- The United States should reshore enough leading-edge logic capacity to meet 100 percent of U.S. demand through 2027.

- This brief recommends appropriating at least \$23 billion (62 percent) of CHIPS Act incentives for leading-edge logic capacity. This should be sufficient to meet 100 percent of U.S. consumption of advanced logic chips through roughly 2027, and would encourage Intel, Samsung, and TSMC to maintain or establish long-term presences in the United States.

- Logic chips made by one manufacturer (e.g., Intel) are not direct substitutes for logic chips from another manufacturer (e.g., TSMC) in the event of a shortage. Leading-edge logic incentives should be distributed across Intel, Samsung, and TSMC in proportion to U.S. demand for chips made by each firm. This equates to one fab for Intel, one fab for Samsung, and two fabs for TSMC.

- The United States should reshore one large DRAM fab.

- Since DRAM exhibits high economies of scale, the minimum cost-effective DRAM footprint is a fab with 100,000 wafers per month (WPM) in capacity. This amounts to roughly 6 percent of current global DRAM capacity, which could address the most sensitive U.S. DRAM demand in the event of a major shortage. This will require \$5-10 billion in CHIPS Act funding. 
- DRAM incentives should go to whichever firm can demonstrate the strongest commitment to building future capacity in the United States-perhaps Micron, the only significant DRAM producer headquartered in the United States.

- Any remaining incentives should be used to reshore legacy logic capacity, in coordination with allies.

- The United States could build between two and five legacy logic fabs with \$4-9 billion in incentives. Again, this would not meet full U.S. demand but could be used to cover the most sensitive applications.

- The United States should also encourage alliesparticularly Germany, Japan, and South Korea-to invest in additional legacy capacity, which will help to reduce global dependence on China and Taiwan.

- The United States should engage East Asian allies to assess and coordinate incentives for semiconductor manufacturing.

- While there appears to be agreement on the role of direct subsidies provided by the Chinese government, further studies and greater transparency are needed to better understand the level of incentives East Asian democracies are providing to their chipmakers.

- It is unclear whether negotiation to reduce subsidies in China will be successful. However, there may be a greater chance of coordinating with allies, in particular Taiwan and South Korea, to align incentives and encourage supply chain resiliency and diversity.

Alongside funding, Congress should ensure that U.S. chipmakers have access to ample manufacturing talent and onshore advanced packaging capabilities. Congress should also streamline regulatory processes for building new fabs. These aspects are discussed in forthcoming and previous CSET research. ${ }^{3}$ 


\section{Table of Contents}

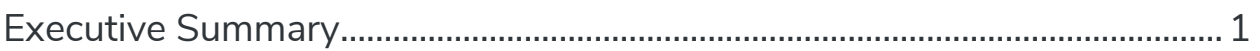

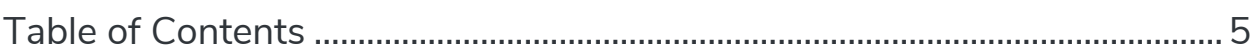

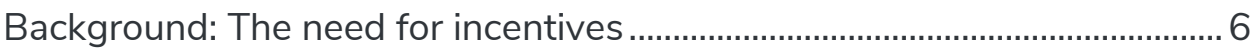

How to distribute manufacturing incentives for leading-edge logic and

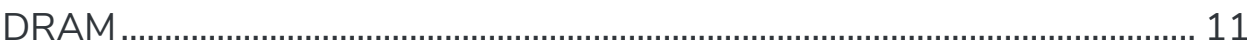

Distributing logic incentives across firms: a portfolio approach............ 12

Distributing leading-edge DRAM incentives: seek long-term commitments to onshore production......................................................... 14

Distributing legacy logic incentives .............................................................. 15

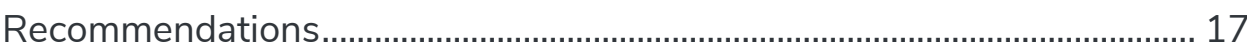

The United States should reshore enough leading-edge logic capacity to meet full U.S. demand through 2027 ...................................................... 17

The United States should reshore one large DRAM fab......................... 17

Remaining incentives should be used to reshore legacy logic capacity, in coordination with allies.............................................................................. 18

The United States should engage East Asian allies to assess and coordinate incentives for semiconductor manufacturing ...................... 18

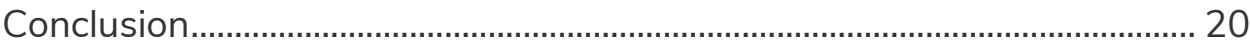

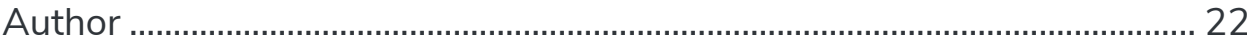

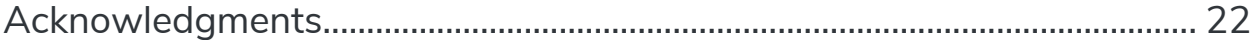

Appendix A: Global and domestic demand for logic and memory chips 23 Appendix B: The consolidation of semiconductor supply in East Asia .... 27

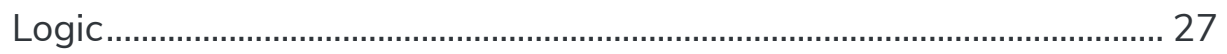

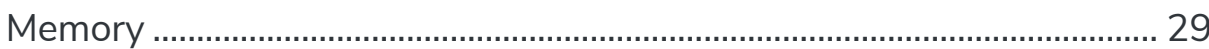

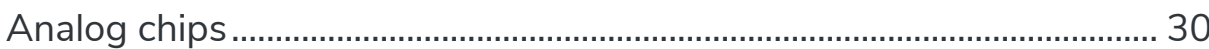

Discretes, optoelectronics, and sensors........................................................ 31

Appendix C: Offshoring by U.S. semiconductor manufacturers ............... 33

Appendix D: The risks of disruptions in East Asian countries .................... 34

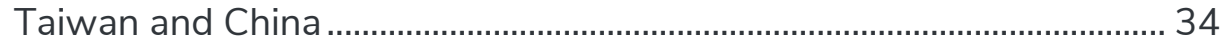

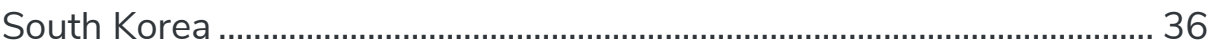

Appendix E: Costs of reshoring leading-edge logic and DRAM fabs ...... 36

Appendix F: Challenges with the Trusted Foundry Program ..................... 38

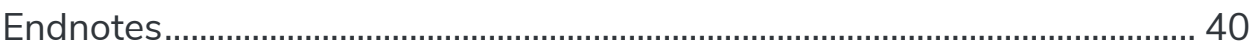




\section{Background: The need for incentives}

In 1955, William Shockley, who would subsequently win a Nobel Prize for his foundational research on semiconductors, made an unorthodox decision. He left his job at AT\&T in Boston-then the hub of U.S. scientific research and technology development-and established a lab of his own in Mountain View, California. In the years that followed, Shockley's lab attracted the best minds in the emerging field of semiconductor physics; Mountain View became the center of semiconductor innovation and, in time, the world's most important technology hub.

Shockley's decision is an example of path dependence, in which small changes at critical moments in time can have long-term consequences. As Paul Krugman has noted, "If there is one single area of economics in which path dependence is unmistakable, it is in economic geography-the location of production in space. The long shadow cast by history over location is apparent at all scales, from the smallest to the largest-from the cluster of costume jewelry firms in Providence to the concentration of 60 million people in the Northeast Corridor."

More than 65 years after Shockley's bold move, path dependence has indeed set in. Today, shifting the economic geography of the semiconductor industry has become a far more expensive proposition, and the costs are rising each year. This is a problem for two reasons:

First, as the ongoing chip shortage has revealed, virtually every sector of the U.S. economy relies on steady access to semiconductors. This includes the U.S. government and military, which account for a small but important share of U.S. chip consumption. Leading-edge logic and memory chips are required to ensure that the Department of Defense (DOD), the Department of Energy (DOE), and the intelligence community continue to field the most advanced computing capabilities. And virtually all military technologies, from vehicles to weapons systems, require legacy logic and analog chips that are cheaper and hardier than the most advanced chips. 
Second, U.S. incumbency advantages in chipmaking are no longer as strong as they once were. Since 1990, much of the world's chip manufacturing capacity has shifted from the United States to East Asia-particularly South Korea, Taiwan, and China. Today, incentivizing the construction of a single leading-edge fab in the United States - rather than Taiwan, for example-will cost roughly \$3-5 billion in government incentives. Ten years from now, the price will be roughly three times higher.

To reverse this trend and sustain U.S. incumbency advantages into the future, Congress passed the CHIPS for America Act, which became law at the start of 2021, authorizing the Department of Commerce to administer tens of billions of dollars in federal grants with the aim of incentivizing major chipmakers to increase manufacturing capacity in the United States. ${ }^{5}$ However, incentives will need to be carefully targeted if they are to have the desired long-term impacts. Estimates from the Semiconductor Industry Association (SIA) and the Boston Consulting Group suggest that even $\$ 50$ billion in funding for the CHIPS Act ( $\$ 11$ billion more than will likely be appropriated) would result in a modest 1 to 2 percentage point increase in the U.S. share of global semiconductor manufacturing capacity, from 12 percent to 13 or 14 percent. $^{6}$

Policymakers must ensure that the U.S. government focus incentives on reshoring the types of chipmaking capacity that matter most to U.S. economic and national security, and that have the potential to change the geography of chip manufacturing over the long term. This brief recommends that incentives focus on leading-edge logic chips (top priority) and dynamic random access memory, or DRAM, (second priority), and direct only limited funding toward legacy chips (third priority). Compared with other chips, leading-edge logic chips are particularly critical to national security, make up a large part of U.S. and global chip consumption, and face especially significant risks of disruptions in supply over the coming decade (Table 1). DRAM and legacy logic are also critical to national security, face significant risks of disruptions, and should be the focus of any remaining funds. 
Table 1. The relative need for reshoring across types of semiconductor devices

\begin{tabular}{|c|c|c|c|c|}
\hline Device & $\begin{array}{l}\text { Current U.S. } \\
\text { capacity as a } \\
\text { percentage } \\
\text { of global } \\
\text { capacity, } \\
2021\end{array}$ & $\begin{array}{l}\text { Worldwide revenue } \\
\text { from sensitive } \\
\text { applications in USD } \\
\text { and as a percentage } \\
\text { of global } \\
\text { consumption, } 2019^{7}\end{array}$ & $\begin{array}{l}\text { Concentration } \\
\text { of global } \\
\text { capacity in } \\
\text { one at-risk } \\
\text { country/ } \\
\text { region, } 2021^{8}\end{array}$ & $\begin{array}{l}\text { Recommended } \\
\text { funding }\end{array}$ \\
\hline $\begin{array}{l}\text { Leading-edge } \\
\text { ( } 5 \mathrm{~nm} \text { ) logic } \\
\text { foundry }^{9}\end{array}$ & None & $25 \% *$ & $\begin{array}{l}85 \% \text { in } \\
\text { Taiwan, 15\% } \\
\text { in South Korea }\end{array}$ & $\begin{array}{l}1^{\text {st }} \text { priority: At } \\
\text { least } \$ 23 \\
\text { billion }\end{array}$ \\
\hline DRAM & $1.4 \%$ & $22 \%$ & $\begin{array}{l}49 \% \text { in South } \\
\text { Korea; } 42 \% \text { in } \\
\text { China and } \\
\text { Taiwan }\end{array}$ & $\begin{array}{l}2^{\text {nd }} \text { priority: } \\
\$ 5-10 \text { billion }\end{array}$ \\
\hline $\begin{array}{l}\text { Legacy logic } \\
\text { (>16 nm) }\end{array}$ & $8 \%$ & $25 \% *$ & $\begin{array}{l}63 \% \text { in China } \\
\text { and Taiwan }\end{array}$ & $\begin{array}{l}3^{\text {rd }} \text { priority: } \\
\text { Any remaining } \\
\text { incentives }\end{array}$ \\
\hline NAND flash & $4 \%$ & $3 \%$ & $\begin{array}{l}33 \% \text { in South } \\
\text { Korea }\end{array}$ & \multirow[t]{5}{*}{ None } \\
\hline Discretes & $4 \%$ & $45 \%$ & $33 \%$ in China & \\
\hline Optoelectronics & $7 \%$ & $18 \%$ & $\begin{array}{l}44 \% \text { in China } \\
\text { and Taiwan }{ }^{10}\end{array}$ & \\
\hline Sensors & $35 \%$ & $44 \%$ & $\begin{array}{l}15 \% \text { in China } \\
\text { and Taiwan }\end{array}$ & \\
\hline Analog & $23 \%$ & $29 \%$ & $\begin{array}{l}\text { U.S. is the top } \\
\text { manufacturer }\end{array}$ & \\
\hline
\end{tabular}

Sources: Various — see Appendices A and B. Red indicates higher vulnerability to future shortages.

* The $25 \%$ figure includes both leading-edge and legacy logic, as Gartner ${ }^{\circledR}$ data does not allow users to distinguish sales at different nodes. 
Note that the analysis in this paper focuses on the goal of ensuring resilience to disruptions in the supply of chips from East Asia. This paper does not address the goal of manufacturing trusted chips onshore for use by the U.S. government in highly sensitive (e.g., military) applications. This latter goal is the aim of the Trusted Foundry Program, which has faced challenges since its inception (for more detail, see Appendix F). The U.S. Innovation and Competition Act (USICA), which has passed the Senate, contains $\$ 2$ billion in funding set aside for mature nodes; this funding may be used to ensure that the United States has sufficient onshore capacity to address demand for the analog chips and other semiconductor devices needed for highly sensitive applications such as military technologies. This paper focuses instead on how to spend the remaining $\$ 37$ billion in manufacturing incentives that are not earmarked for mature nodes.

Improving resilience to disruptions in leading-edge logic and DRAM production is achievable with CHIPS Act funding. With \$23 billion in manufacturing incentives, the United States would reshore enough capacity to meet roughly 100 percent of U.S. demand for leading-edge logic through 2027 (or roughly one-third of U.S. demand over the next decade if incentives are staggered). An additional \$5-10 billion should be used to incentivize the construction of one large leading-edge DRAM fab. Any remaining incentives should go toward either additional leading-edge logic capacity or up to five legacy logic fabs (third priority).

In addition to insuring against the possibility of major disruptions in chip manufacturing in East Asia, these incentives will level the playing field with Taiwan and South Korea which offer significant government support and subsidies to their respective chip industries. Unfortunately, it is unlikely that the United States will persuade China to reduce its heavy incentives for the Chinese semiconductor industry, so further U.S. incentives may be necessary going forward to continue to counter China's incentives. ${ }^{11}$ However, over the longer term the United States should engage its East Asian allies to better understand the amount of incentives offered by the Taiwanese and South Korean 
governments, and to coordinate incentives in order to reduce the risk of a race to the bottom.

CHIPS Act funding could help cement the United States as a leader in advanced semiconductor manufacturing - but success is not guaranteed without the effective allocation of funding. Many different chipmakers, with a wide range of manufacturing capabilities, hope to capture a slice of CHIPS Act funding. A recent analysis identified 28 separate chipmakers that will likely compete for CHIPS Act incentives. ${ }^{12}$ These firms include defense contractors (e.g., Raytheon) which produce highly customized (i.e., high mix) chips at low volumes and will likely compete for the $\$ 2$ billion in incentives earmarked for mature technology nodes. They also include leading makers of logic (e.g., Intel), memory (e.g., Micron), and analog (e.g., Texas Instruments) chips, as well as firms focused on the production of legacy chips (e.g., GlobalFoundries).

With so many chipmakers competing for CHIPS incentives, policymakers will need to craft eligibility criteria that prioritize recipients of those incentives carefully. The next section describes in detail how to distribute CHIPS incentives between DRAM and logic, and among specific chipmakers. The third section of the brief concludes with recommendations for policymakers seeking to maximize U.S. resilience to potential disruptions in chip manufacturing in East Asia. 
How to distribute manufacturing incentives for leadingedge logic and DRAM

In choosing where to allocate CHIPS Act funds, policymakers should carefully weigh the costs and benefits of investing in leading-edge logic, DRAM, and legacy logic capacity. Table 2 presents our recommended distribution of incentives, with leadingedge logic receiving a higher proportion of total funding due to its greater strategic importance and the higher risks of disruptions in Taiwan. ${ }^{13}$ Estimates shown in Table 2 are approximate, and even higher investments in leading-edge logic could be justified.

Policymakers who are especially concerned about risks of disruptions in Taiwan may prefer to focus more incentives on future generations of logic, since the proposed incentives would remain current only through 2027. Table 2 simply illustrates what is possible with $\$ 37$ billion in incentives. This is the amount of funding for Commerce that is not earmarked for mature technology nodes in the Senate-passed USICA that will likely be appropriated in 2022.

Table 2. Scenario for distributing manufacturing incentives across logic and DRAM

\begin{tabular}{|l|c|c|c|c|}
\hline Device & \multicolumn{2}{|c|}{ Advanced logic } & DRAM & Legacy logic \\
\hline $\begin{array}{l}\text { First year of } \\
\text { production }\end{array}$ & 2023 & 2025 & $2023-2025$ & $2023-2025$ \\
\hline Node & 3 & 2 & $1 b$ or $1 \mathrm{c}$ & $16-90$ \\
\hline $\begin{array}{l}\text { Capacity } \\
\text { recommended } \\
\text { (300mm wafers } \\
\text { per month }\end{array}$ & $\begin{array}{c}69,000(\sim 2 \\
\text { fabs) }\end{array}$ & $\begin{array}{c}76,000(\sim 2 \\
\text { fabs) }\end{array}$ & $100,000(\sim 1$ fab) & $\begin{array}{c}\text { Up to } \\
\text { to 5 fabs) }\end{array}$ \\
\hline $\begin{array}{l}\text { U.S. demand } \\
\text { met }\end{array}$ & $100 \%$ & $100 \%$ & $\begin{array}{c}\text { Critical } \\
\text { applications }\end{array}$ & $\begin{array}{c}\text { Critical } \\
\text { applications }\end{array}$ \\
\hline $\begin{array}{l}\text { Cost to U.S. } \\
\text { Government }\end{array}$ & \$10B & \$13B & \$5-10B & \$4-9B \\
\hline
\end{tabular}

Source: Derived from Appendix E. 
Note: Fabs take two to four years to construct, equip, and ramp up to full capacity. Depending on the speed with which chipmakers expect to build their fabs, it may be preferable to target future nodes with incentives rather than those shown in Table 2 (a 3 nanometer logic fab will no longer be leading edge in 2025). Targeting future nodes will raise costs, so the estimates in Table 2 should be taken as a lower bound on the incentives required to meet the proposed targets for leading-edge logic. ${ }^{15}$

\section{Distributing logic incentives across firms: a portfolio approach}

With $\$ 23$ billion in spending on logic capacity, the United States could ensure the construction of four leading-edge logic fabsenough to meet roughly 100 percent of U.S. demand for the next two ( $3 \mathrm{~nm}$ and $2 \mathrm{~nm}$ ) generations of logic chips (see Appendix E). However, U.S. demand for cutting-edge logic chips encompasses chips made by three different chipmakers: Intel, Samsung, and TSMC. Unfortunately, this capacity is not interchangeable: Intel fabs cannot directly meet the demand for Samsung and TSMC capacity: ${ }^{16}$ and Samsung and TSMC cannot meet demand for Intel capacity (at least not in the relevant time).

Incentives for four new logic fabs should therefore be distributed approximately in proportion to U.S. demand for chips made by Intel, Samsung, and TSMC respectively. Most of today's leadingedge chips consumed in the United States are used in consumer electronics and related industries, with Intel focusing on chips for PCs and servers; Samsung focusing on chips for tablets and smartphones; and TSMC providing chips across all major markets. Based on historical and projected U.S. demand for these devices, CSET estimates that roughly 25 percent of U.S. consumption of leading-edge logic chips can be attributed to Intel; 20 percent to Samsung; and 55 percent to TSMC (Table 3). ${ }^{17}$ 
Table 3. Estimated U.S. demand for leading-edge logic chips in unit shipments per year, 2021

\begin{tabular}{|l|r|r|l|l|}
\hline Chipmaker & Smartphones $^{18}$ & Tablets $^{19}$ & $\begin{array}{l}\text { Personal } \\
\text { computers, } \\
\text { gaming } \\
\text { consoles, and } \\
\text { servers }^{20}\end{array}$ & Total \\
\hline Intel & 0 & 0 & 66 million & $\begin{array}{r}66 \text { million } \\
(25 \%)\end{array}$ \\
\hline Samsung & 35 million & 18 million & & 0 \\
\hline TSMC & 70 million & 22 million & 54 million & $\begin{array}{r}146 \text { million } \\
(20 \%)\end{array}$ \\
\hline Total & 105 million & 40 million & 120 million & $\begin{array}{r}265 \text { million } \\
(100 \%)\end{array}$ \\
\hline
\end{tabular}

Source: CSET estimates based on Statista market data.

Note: Demand estimates correspond to end-use consumption by businesses and consumers based in the United States. Thus, an iPhone purchased in China is not counted as U.S. consumption, despite the fact that iPhones are made by Apple, a U.S.-headquartered firm.

If we divide fabs based on these estimates, then incentives should be distributed to support one new U.S. fab for Intel; one new U.S. fab for Samsung; and two new U.S. fabs for TSMC. This distribution of incentives would allow the United States to meet approximately 100 percent of U.S. demand for leading-edge chips made by each of the world's three leading chipmakers. Each of these chipmakers already have existing plans to build new advanced logic fabs in the United States, which appear to be contingent on receiving CHIPS Act funding. ${ }^{21}$ Of course, if these plans are not contingent on CHIPS Act funding, then funding could be saved and invested in future generations of leading-edge logic. In this case, future incentives should still aim to follow a similar 11-2 distribution of fabs across Intel, Samsung, and TSMC. ${ }^{22}$ This 
approach will help meet U.S. demand from domestically-based fab sources and guard against foreign supply disruptions to two foreign chipmakers critical to U.S. industry.

\section{U.S.-headquartered chipmakers build most new capacity offshore by default.}

Much of the capacity of leading U.S.-headquartered chipmakers is located outside of the United States. For example, Analog Devices has 38 percent of capacity offshore, Intel has 61 percent offshore, and Micron has 79 percent offshore. ${ }^{23}$ Offshoring appears to be part of a long-term trend. Among the fabs that these firms constructed prior to 2000 that are still operational, 100 percent are located in the United States; by contrast, among their fabs constructed in 2015 or later, only around 15 percent of capacity is in the United States. ${ }^{24}$

\section{Distributing leading-edge DRAM incentives: seek long-term commitments to onshore production}

A second priority for manufacturing incentives is DRAM capacity. The entirety of global DRAM demand is met by three companies: Micron, Samsung, and SK hynix. Historically, the supply of DRAM has been resilient because products are largely substitutable among these three producers. However, as noted in the previous section, approximately 50 percent of leading-edge DRAM is currently located in South Korea, with the remainder (43 percent) almost entirely located in Taiwan and China. The United States has near-zero DRAM capacity: the U.S.-headquartered firm Micron does not currently have any of its leading-edge DRAM capacity located in the United States.

Establishing even a minimal amount of leading-edge DRAM capacity in the United States would require a significant portion of $\mathrm{CHIPS}$ Act manufacturing incentives. Economies of scale are especially strong in the DRAM business, so it typically is not cost effective to build less than 100,000 wafers per month (WPM) in capacity at a time. Fortunately, DRAM firms typically upgrade their 
fabs consistently, so a newly-built leading-edge fab may remain at or near the leading edge for years if its owner commits to making consistent upgrades. We estimate that $\$ 5-10$ billion in federal incentives would be required to persuade a DRAM fab to build a new 100,000 WPM fab in the United States. ${ }^{25}$

Because of the large-scale and long-term nature of DRAM investments, any DRAM-focused incentives should be crafted and distributed to companies with a demonstrated strategy for longterm viability in, and commitment to, the United States. As the only U.S.-headquartered memory chipmaker, Micron may be a good candidate for incentives. While Micron does not currently have significant DRAM capacity in the United States, as an American company it may be more likely to invest in the United States longterm than its South Korean competitors.

\section{Distributing legacy logic incentives}

Prioritizing leading-edge logic and DRAM should offer a return on investment that lasts well over a decade into the future. ${ }^{26}$ However, there are many applications for which highly advanced logic chips will likely never be used. For example: all modern vehicles, from sports cars to military humvees, incorporate thousands of semiconductors, many of which are very cheap and do not require high speed or efficiency. ${ }^{27}$ The United States is losing the ability to manufacture some of these legacy chips onshore, typically not because of technical challenges but rather because older fabs have closed down and are not being replaced. ${ }^{28}$

It is beyond the scope of this report to assess all such near-term gaps in U.S. legacy logic capacity and their impacts on U.S.

government procurement. But any remaining incentives could be used to cheaply build additional legacy logic capacity, or help existing fabs upgrade their lines or acquire the equipment required so that military and other especially sensitive application areas continue to have access to onshore capacity. We estimate that with \$4-9 billion remaining in CHIPS Act incentives, two to five legacy logic fabs could be built in the United States. ${ }^{29}$ Even the

minimum of two fabs could be valuable if targeted to meet the 
most sensitive U.S. demand for legacy logic. Note that, in addition to the $\$ 37$ billion in unrestricted manufacturing incentives, the U.S. Innovation and Competition Act includes $\$ 2$ billion in incentives set aside for mature technology nodes. This additional \$2 billion could also go toward legacy logic capacity, but it may be consumed by other types of chipmakers such as the manufacturers of specialized analog chips used in military and other sensitive applications. As stated above, this report does not assess priorities for this additional \$2 billion in incentives.

One alternative to investing in domestic legacy logic is coordinating incentives with U.S. allies. For example, Germany, Japan, and Singapore all have existing legacy logic capacity and have comparative advantages in these markets. Rather than competing with these countries for the same fabs, if these countries focused their incentives on legacy logic, this could free up the United States to focus more of its incentives on leading-edge logic. 


\section{Recommendations}

\section{The United States should reshore enough leading-edge logic capacity to meet full U.S. demand through 2027}

Leading-edge logic chips are critical to U.S. national and economic security, and their production is highly concentrated in Taiwan, which faces significant risks of environmental and political disruptions over the coming decade. Incentives aimed at establishing leading-edge logic capacity in the United States will significantly reduce U.S. dependence on Taiwan. They will also help attract suppliers of materials and equipment to the United States, and draw top engineering talent from the United States and around the world, strengthening the U.S. semiconductor innovation ecosystem. Thus, investments in the leading edge will have benefits both today and well into the future.

This brief therefore recommends appropriating the majority (at least \$23 billion) of CHIPS Act manufacturing incentives for building sufficient onshore capacity to meet 100 percent of U.S. demand for leading-edge logic in the near term. Logic incentives should ideally be distributed across the three leading logic manufacturers, in proportion to each firm's share of leading-edge logic consumption by the United States. To reiterate, Intel accounts for roughly 25 percent of U.S. leading-edge logic consumption ( 1 fab), Samsung accounts for roughly 20 percent ( 1 fab), and TSMC accounts for roughly 55 percent ( 2 fabs).

\section{The United States should reshore one large DRAM fab}

The United States should also aim to establish one large DRAM fab onshore. Since DRAM exhibits high economies of scale, the minimum cost-effective DRAM footprint is a fab with 100,000 WPM in capacity. This amounts to roughly 6 percent of global DRAM capacity, which could address the most sensitive U.S. DRAM applications in the event of a major disruption in supply from South Korea, Taiwan, or China. Incentivizing the construction of one DRAM fab will require \$5-10 billion. DRAM incentives should be given to whichever firm can demonstrate a long-term 
commitment to building future capacity in the United Statesperhaps Micron, the only major DRAM producer headquartered in the United States.

\section{Remaining incentives could be used to reshore legacy logic capacity, in coordination with allies}

The United States could build between two and five legacy logic fabs with the remaining \$4-9 billion in non-earmarked incentives. Any legacy logic incentives should target gaps in onshore capacity which are especially important for national security applications. Incentives should also be coordinated with U.S. allies-in particular, Germany, Japan, and South Korea, each of which already has some preexisting legacy logic capacity. Capacity in these countries will help ease the severity of a shortage in the event of a major disruption to manufacturing in Taiwan and China. If U.S. allies invest sufficiently in legacy logic capacity, then the United States could focus its incentives more heavily on leading-edge logic.

\section{The United States should engage East Asian allies to assess and coordinate incentives for semiconductor manufacturing}

Taiwan, South Korea, and especially China offer significant subsidies and government support to their chip industries. CHIPS Act incentives are an important immediate counter to these incentives, leveling the playing field and helping to address the United States' high degree of semiconductor dependence on East Asia. It is unlikely that the United States will persuade China to reduce its support for the Chinese semiconductor industry, further U.S. incentives may be necessary going forward to continue to counter China's incentives. ${ }^{30}$ However, over the longer term the United States should engage its East Asian allies to better understand the extent of the incentives offered by the Taiwanese and South Korean governments, and to coordinate incentives in order to reduce the risk of a race to the bottom.

This process must begin with establishing how much Taiwan and South Korea currently subsidize their chipmakers. The most credible existing estimates have been made by SIA, but some 
within the industry have disputed these estimates. Greater transparency by governments would allow for a clearer understanding of the current level of incentives, and provide a starting point for negotiations around future incentives. 


\section{Conclusion}

In the mid-twentieth century, U.S. researchers and engineers invented the semiconductor. In so doing, they put the United States at the center of what would become a half trillion dollar industry powering virtually every sector of the global economy. The United States still benefits from its incumbency advantage in many parts of the semiconductor supply chain, from chip design to manufacturing equipment to electronic design automation software to core IP. But in chip manufacturing itself, U.S. leadership now faces serious challenges. Firms in Taiwan and South Korea have increased their market shares and begun to displace U.S. chipmakers at the leading edge.

If CHIPS Act manufacturing incentives focus on the legacy chips that have made headlines over the last year, the United States may wind up on the wrong side of an incumbency advantagedependent on the two countries that managed to catch up to the leading edge at a time when that was still possible, and stay there until it was not. Ten years from now, incentivizing the construction of a single leading-edge logic fab will likely cost more than $\$ 10$ billion, and semiconductors will be even more essential to the global economy. At this point, it may be simply infeasible, even for the United States, to reestablish its position at the leading-edge of what is arguably the world's most important industry. Like China, the United States may find itself in a quandary, highly dependent on Taiwan and South Korea for the most powerful computer chips, and unable to pay the price of catching up.

CHIPS Act incentives, if targeted toward reshoring the most advanced logic and DRAM chips, can keep the United States at the leading edge in chipmaking for the foreseeable future. The United States still has an ecosystem-composed of leading design firms, ample land, IP protections, and top global talent-that is highly appealing to both U.S. and foreign chipmakers. This brief has argued that a budget of $\$ 37$ billion in non-earmarked incentives could level the playing field with East Asia and supercharge this ecosystem, while greatly increasing U.S. resiliency to potential disruptions in semiconductor manufacturing in East Asia. 
Shifting the geography of semiconductor manufacturing is much harder today than it was in 1955 when Shockley moved to Mountain View. But CHIPS Act incentives, carefully distributed, could have long-term effects. The Department of Commerce should focus first on funding leading-edge logic, second on leading-edge DRAM, and third on legacy logic chips. This distribution of funding will address the most immediate U.S. national and economic security needs while keeping the United States on the right side of the chipmaking incumbency advantage for years to come. 


\section{Author}

Will Hunt is a research analyst with CSET.

\section{Acknowledgments}

For helpful discussions, comments, and input, great thanks go to Igor Mikolic-Torreira, Owen Daniels, John VerWey, Helen Toner, Rita Konaev, Andrew Imbrie, Abe Newman, Ashwin Acharya, Lorand Laskai, Michael Fritze, Shelton Fitch, Lynne Weil, Dewey Murdick, and two anonymous reviewers. The author is solely responsible for all mistakes.

\section{(c) $(1)(8)$}

(c) 2022 by the Center for Security and Emerging Technology. This work is licensed under a Creative Commons Attribution-Non Commercial 4.0 International License.

To view a copy of this license, visit https://creativecommons.org/licenses/by-nc/4.0/. 


\section{Appendix A: Global and domestic demand for logic and memory chips}

\section{Certain types of semiconductor devices account for a}

disproportionate share of global semiconductor sales. This appendix leverages global and domestic consumption data from Gartner's Semiconductor Forecast and the Semiconductor Industry Association's End-Use Survey to explore variation in demand across different devices. The results indicate that an interruption in the supply of logic and DRAM devices would be especially damaging to U.S. national and economic security.

Logic and, to a lesser degree, DRAM chips stand out from other semiconductor devices in terms of their economic and national security importance. Table 4, below, shows Gartner's estimates of worldwide semiconductor revenues in 2019 broken down by type of device and CSET's coding of application sensitivity. ${ }^{31}$ Logic and DRAM chips combined accounted for nearly half of both total consumption and sensitive consumption worldwide. Together with flash memory chips these devices are expected to account for 90 percent of growth in the semiconductor industry over the next decade. ${ }^{32}$

Table 4. Worldwide semiconductor revenues by device and application sensitivity (in millions of USD), 2019

\begin{tabular}{|c|c|c|c|c|c|c|c|c|c|c|}
\hline \multirow[b]{2}{*}{ Sensitivity } & \multicolumn{9}{|c|}{ Device } & \multirow[b]{2}{*}{ Total } \\
\hline & Logic & $\begin{array}{l}\text { DRAM } \\
\text { Memory }\end{array}$ & \begin{tabular}{|l} 
NAND \\
Flash \\
Memory
\end{tabular} & $\begin{array}{l}\text { Emerging } \\
\text { and Other } \\
\text { Memory }\end{array}$ & Analog & Discrete & $\begin{array}{l}\text { Non- } \\
\text { Optical } \\
\text { Sensors }\end{array}$ & $\begin{array}{l}\text { Opto- } \\
\text { electronics }\end{array}$ & $\begin{array}{l}\text { Other } \\
\text { ASICs }\end{array}$ & \\
\hline Low & $\$ 102,657$ & $\$ 48,253$ & $\$ 41,371$ & $\$ 3,894$ & $\$ 16,529$ & $\$ 12,308$ & $\$ 5,699$ & $\$ 28,814$ & $\$ 65,775$ & $\$ 325,301$ \\
\hline High & $\$ 34,424$ & $\$ 13,957$ & $\$ 1,289$ & $\$ 929$ & $\$ 6,709$ & $\$ 10,095$ & $\$ 4,516$ & $\$ 6,411$ & $\$ 18,707$ & $\$ 97,036$ \\
\hline Total & $\$ 137,081$ & $\$ 62,210$ & $\$ 42,660$ & $\$ 4,823$ & $\$ 23,238$ & $\$ 22,403$ & $\$ 10,215$ & $\$ 35,225$ & $\$ 84,482$ & $\$ 422,337$ \\
\hline
\end{tabular}

Source: Chart created and calculations performed by CSET based on Gartner research. ${ }^{33}$ 
The importance of logic and memory chips increases when we focus on the United States. SIA's End-Use Survey (Figures 1, 2, and 3 below) tracks the value of chips that are incorporated into electronic devices such as PCs and servers manufactured in the United States. ${ }^{34}$ The data suggests that, relative to the rest of the world, U.S. device manufacturers demand an especially high proportion of logic and DRAM chips, and a lower proportion of analog chips as well as discretes, optoelectronics, and other semiconductor devices. ${ }^{35}$

Figure 1. North and South American electronic device manufacturers' consumption of semiconductors relative to other regions, $2019^{36}$

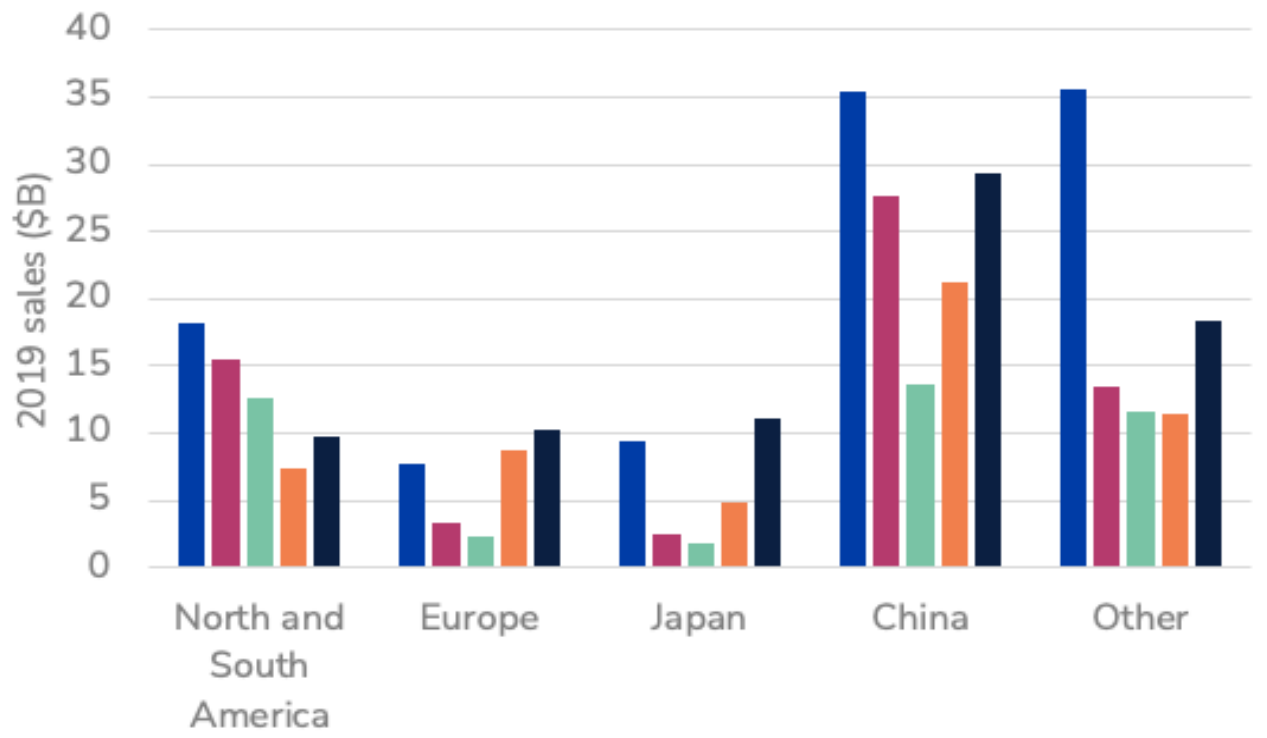

Ship-to location

- Logic aDRAM a Flash analog a OSDA

Source: SIA End-Use Survey.

Note: OSDA represents discretes, optoelectronics, and actuators.

The relatively high logic and memory consumption in North and South America is partly driven by the region's large computer and communications sectors relative to other regions. These sectors include personal computers and smartphones (coded by CSET as low sensitivity) as well as servers (coded as high sensitivity). 
Meanwhile, the automotive and industry sectors-where analog, optoelectronics, discretes, and other devices are more importantare smaller within North and South America. Within this region, logic chips account for a large share of demand in the communications industry, as well as more than half of the semiconductor demand of the small but sensitive "government" sector, with analog chips making up the remainder in that sector (Figure 3).

Figure 2. Electronic device manufacturers' consumption of chips by sector and region, 2019

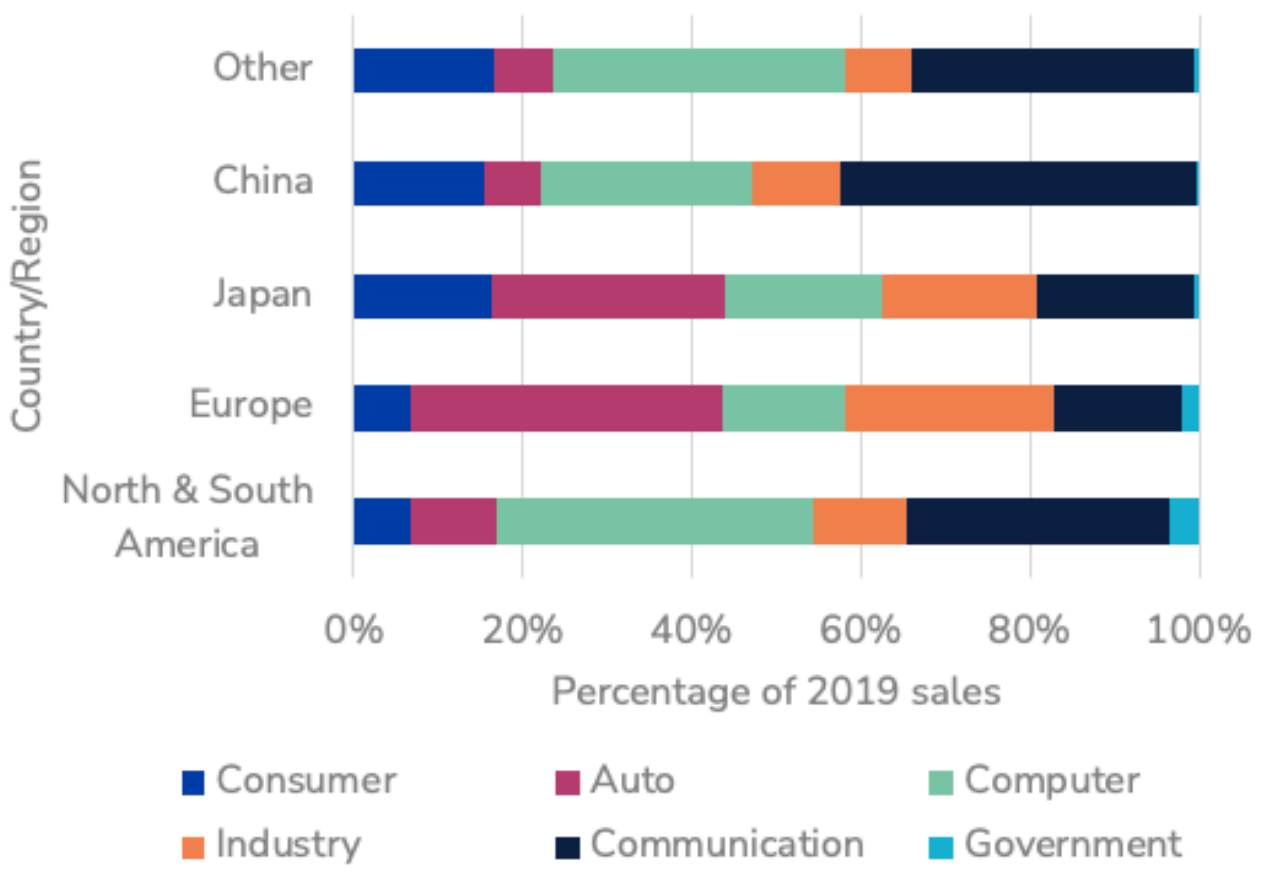

Source: SIA End-Use Survey. 
Figure 3. North and South American electronic device manufacturers' consumption of chips by semiconductor device and sector, 2019

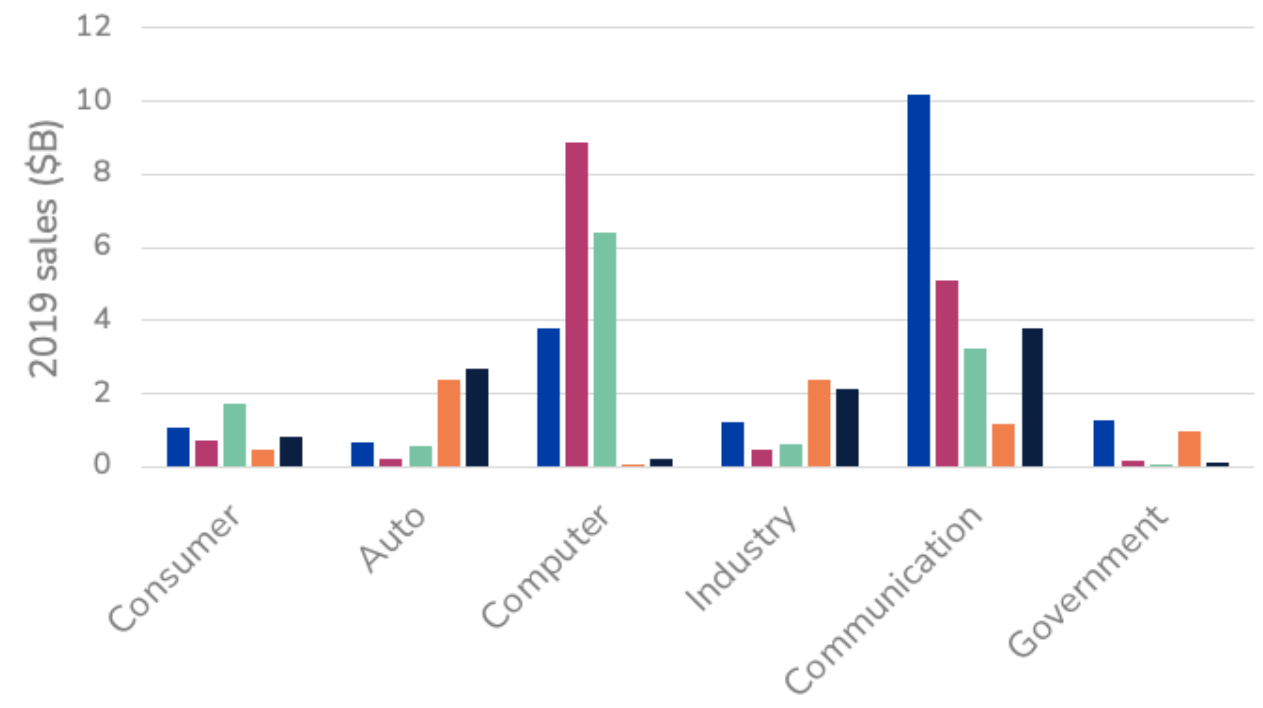

Sector

- Logic aDRAM Flash Analog a OSDA

Source: SIA End-Use Survey.

Note: OSDA represents discretes, optoelectronics, and actuators.

These results come with two important caveats. First, revenue is only a rough proxy for importance. The clearest example of this is the smartphone market, which is less sensitive than other application areas, but accounts for a large portion of North and South American-as well as global-semiconductor consumption of logic and memory chips (especially expensive, leading-edge chips). We attempted to correct for this by sorting applications by sensitivity, but even within sensitive applications there remains considerable variation in strategic importance-for example, military applications are more sensitive than servers, which include everything from game servers (less sensitive) to supercomputer servers (more sensitive).

Second and relatedly, many electronics depend on the integration of a wide range of semiconductor devices. For example, the motherboard of a personal computer typically has dozens of 
components, not all of which are memory and logic chips. A shortage of a single inexpensive component could thus have significant impacts on the market for PCs if it has no readily available substitute. An analysis of the whole range of electronic components and the availability of substitutes is beyond the scope of this report, but we do recommend limited incentives for legacy logic chips partly for this reason.

Overall, however, these findings show that disruptions in the supply of semiconductor devices - particularly logic or DRAM chips-could have especially significant economic and strategic consequences, both globally and within the United States.

\section{Appendix B: The consolidation of semiconductor supply in East Asia}

Not only do logic and memory chips comprise an especially high fraction of semiconductor consumption, they also likely pose the highest risks of future disruptions due to the concentration of logic and memory manufacturing capacity in East Asia. This is especially true for leading-edge logic and DRAM devices. By contrast, supply is relatively diversified for other semiconductor devices such as analog chips and discretes, and the United States has considerable capacity in low-volume, high-mix compound semiconductors used for sensitive military applications.

\section{Logic}

Logic capacity is concentrated in East Asia and especially in Taiwan, across both legacy and-especially-leading-edge nodes. As shown in Table 5 below, only TSMC (Taiwan) and Samsung (South Korea) have any commercially-viable capacity at the leading edge ( $5 \mathrm{~nm}$ and below). ${ }^{37}$ Fortunately, the U.S. firm Intel has considerable capacity in both the United States and Israel at its 10 $\mathrm{nm}$ node (which is competitive with TSMC and Samsung's $7 \mathrm{~nm}$ node), and much of Intel's capacity goes toward more sensitive applications such as servers. Unfortunately, this capacity is only available to Intel and not to fabless firms, who depend entirely on Samsung and TSMC for access to leading-edge logic foundry 
capacity. Overall, the lack of leading-edge logic capacity in the United States is concerning, given the economic importance of these chips, coupled with the risks of a disruption in logic manufacturing in Taiwan and China.

Table 5. Logic capacity (in 200 mm equivalent ${ }^{38}$ WPM) by country/region and node, 2021

\begin{tabular}{|c|c|c|c|c|c|c|c|c|}
\hline $\begin{array}{l}\text { Country/ } \\
\text { Region }\end{array}$ & $4-5 \mathrm{~nm}$ & 6-7 nm & $8-10 \mathrm{~nm}$ & $11-16 \mathrm{~nm}$ & $20-40 \mathrm{~nm}$ & $55-90 \mathrm{~nm}$ & $100 \mathrm{~nm}+$ & Total \\
\hline Taiwan & 360,000 & 371,250 & & 236,250 & $1,192,500$ & 293,750 & $1,173,288$ & $3,627,038$ \\
\hline China & & & & 123,750 & 533,250 & 371,250 & $1,202,406$ & $2,230,656$ \\
\hline U.S. & & $81,000^{*}$ & $180,000^{\dagger}$ & 501,750 & 112,500 & 88,500 & 365,969 & $1,329,719$ \\
\hline $\begin{array}{l}\text { Europe \& } \\
\text { Middle East }\end{array}$ & 10,125 & & 168,750 & 254,250 & 150,750 & 106,000 & 205,003 & 894,878 \\
\hline S. Korea & 168,750 & & 67,500 & & 153,750 & 310,000 & 85,000 & 785,000 \\
\hline Japan & & & & & 119,250 & 161,000 & 404,896 & 685,146 \\
\hline SE Asia & & & & & 273,375 & & 249,450 & 522,825 \\
\hline Total & 538,875 & 452,250 & 416,250 & $1,116,000$ & $2,535,375$ & $1,330,500$ & $3,686,012$ & $10,075,262$ \\
\hline
\end{tabular}

Source: World Fab Forecast.

The concentration of legacy capacity in Taiwan, and to a lesser degree in China, is also cause for some concern. Taiwan and China together have almost two-thirds of legacy logic capacity. While legacy nodes contribute less to global logic revenues than leadingedge nodes, they are nevertheless important: indeed, the current shortage of chips for automakers demonstrates that a shortage of even legacy chips can be highly economically damaging. In the worst case, legacy chips can be redesigned for production in leading-edge fabs, but this is expensive and takes months at minimum. Note, however, that the United States, Europe, South

${ }^{*}$ This is Intel capacity which is not yet commercially available.

'This is Intel's $10 \mathrm{~nm}$ capacity which is competitive with TSMC and Samsung's 7 nm nodes. 
Korea, and Japan all have significant legacy logic capacity as well, making legacy logic a somewhat lower priority than leading-edge logic.

\section{Memory}

Like logic capacity, global memory capacity is concentrated in East Asia. The geographic concentration of DRAM production is especially severe (Table 6). Indeed, South Korea's dominance of DRAM is comparable to TSMC's dominance in high-end logic. South Korean firms Samsung (44 percent market share) and SK hynix (29 percent) together enjoy a majority of the DRAM market. The only other major player is the U.S. firm Micron (22 percent): but Micron's advanced DRAM capacity is based almost entirely in Japan and Taiwan.

Table 6. DRAM capacity (in 200mm equivalent WPM) by node and country/region, 2021

\begin{tabular}{|l|r|r|r|r|r|r|r|r|r|r|}
\hline $\begin{array}{l}\text { Countryl } \\
\text { Region }\end{array}$ & $\mathbf{1 5} \mathbf{n m}$ & $\mathbf{1 6} \mathbf{n m}$ & $\mathbf{1 7} \mathbf{n m}$ & $\mathbf{1 8} \mathbf{n m}$ & $\mathbf{1 9} \mathbf{n m}$ & $\mathbf{2 0 ~ n m}$ & $\mathbf{2 1} \mathbf{n m}$ & $\mathbf{2 5} \mathbf{n m}$ & $\mathbf{3 0} \mathbf{n m}$ & Total \\
\hline S. Korea & $\mathbf{7 6 5 , 0 0 0}$ & 353,250 & 546,750 & 319,500 & & & & & & $1,984,500$ \\
\hline Taiwan & 704,250 & & & & & 168,750 & & 78,750 & 951,750 \\
\hline China & & & & 191,250 & 270,000 & & 247,500 & & & 708,750 \\
\hline Japan & 243,000 & & & & & & & & & 243,000 \\
\hline U.S. & & & & & & & & & 58,500 & 58,500 \\
\hline Total & $1,712,250$ & 353,250 & 546,750 & 510,750 & 270,000 & 168,750 & 247,500 & 78,750 & 58,500 & $3,946,500$ \\
\hline
\end{tabular}

Source: World Fab Forecast.

3D NAND flash, the most popular advanced memory chip, has consolidated to a significant but lesser degree in East Asia. Table 7 shows the global distribution of advanced 3D flash capacity by layer count and country of manufacture. Chips with more layers are more advanced, cramming more memory onto a given die. In NAND flash, as in DRAM, U.S.-headquartered firms have located their leading-edge capacity almost entirely outside of the United States: manufacturing capacity for Intel's 144 layer NAND flash is located in China, while Micron's 176 layer NAND flash capacity is located in Singapore. ${ }^{39}$ 
Table 7. NAND flash capacity (in $200 \mathrm{~mm}$ equivalent WPM) by layers and country/region, 2021

\begin{tabular}{|l|r|r|r|r|r|r|r|r|}
\hline $\begin{array}{l}\text { Countryl } \\
\text { Region }\end{array}$ & 3DXP & $\mathbf{1 7 6} \mathbf{n m}$ & $\mathbf{1 6 2} \mathbf{n m}$ & $\mathbf{1 4 4} \mathbf{n m}$ & $\mathbf{1 2 8} \mathbf{n m}$ & $\mathbf{1 1 2} \mathbf{n m}$ & Other & \multicolumn{1}{l}{ Total } \\
\hline Japan & & & 135,000 & & 1,125 & $1,289,250$ & 459,000 & $1,884,375$ \\
\hline S. Korea & & & & & $1,064,250$ & & 405,000 & $1,469,250$ \\
\hline China & & & & 270,000 & & & 774,000 & $1,044,000$ \\
\hline SE Asia & & 132,750 & & & 382,500 & & 67,500 & 582,750 \\
\hline U.S. & 112,500 & & & & & & 119,250 & 231,750 \\
\hline Taiwan & & & & & & & 205,500 & 205,500 \\
\hline Total & 112,500 & 132,750 & 135,000 & 270,000 & $1,447,875$ & $1,289,250$ & $2,030,250$ & $5,417,625$ \\
\hline
\end{tabular}

Source: World Fab Forecast.

\section{Analog chips}

The United States also has analog capacity across all wafer sizes. U.S. firms comprise eight of the top 10 analog firms, and their primary competitor outside the United States is in Europe. On the lower end of the wafer size spectrum, defense firms like Northrop Grumman and Raytheon have significant U.S. footprints.

Table 8. Analog wafer capacity (in 200mm equivalent WPM) by node and country/region, 2021

\begin{tabular}{|l|r|r|r|r|r|r|r|r|r|}
\hline Country/Region & $21-33 \mathbf{n m}$ & $\mathbf{3 4 - 4 6} \mathbf{n m}$ & $\mathbf{4 7 - 7 9} \mathbf{n m}$ & $\mathbf{8 0 - 1 3 0 ~ n m}$ & $\mathbf{1 3 1 - 3 5 0} \mathbf{n m}$ & $\mathbf{3 5 1 - 8 0 0} \mathbf{n m}$ & $\mathbf{8 1 0 - 1 3 0 0 ~ n m}$ & $\mathbf{1 3 1 0} \mathbf{n m +}$ & Total \\
\hline Europe \& Middle East & & & 3,000 & 220,000 & 193,695 & 108,000 & 1,250 & 29,188 & 555,133 \\
\hline U.S. & 45,000 & & 157,500 & 87,000 & 121,938 & 12,541 & 37,383 & 3,500 & 464,861 \\
\hline Japan & & 27,000 & & 119,000 & 159,758 & 19,688 & 2,000 & 3,938 & 331,383 \\
\hline SE Asia & & & & 244,000 & & 52,875 & & & 296,875 \\
\hline China & & & & 30,000 & 90,000 & 31,000 & 44,375 & 703 & 196,078 \\
\hline S. Korea & & & & 55,000 & 105,000 & & & & 160,000 \\
\hline Taiwan & & & & & 37,063 & & & 37,063 \\
\hline Total & 45,000 & 27,000 & 160,500 & 755,000 & 707,453 & 224,103 & 85,008 & 37,328 & $2,041,392$ \\
\hline
\end{tabular}

Source: World Fab Forecast. 


\section{Discretes, optoelectronics, and sensors}

Like logic and DRAM, the production of discretes, optoelectronics, and sensors is concentrated in East Asia. Tables 9, 10, and 11 below show that China, in particular, produces one-third of the world's discretes and 30 percent of the world's optoelectronics. However, most of these devices are relatively straightforward to produce: thus, substitutes are typically available from Japan and Europe, which are also major discrete and optoelectronics producers. China therefore has little incentive to strategically cut off U.S. access to these devices. Meanwhile, the United States is the leading manufacturer of sensors. This does not mean that discretes, optoelectronics, and sensors are unimportant to the U.S. economy or national security, but they appear to pose a lower risk of a dramatic disruption in supply than other devices.

\section{Table 9. Discrete wafer capacity (in $200 \mathrm{~mm}$} equivalent WPM) by country/region, 2021

\begin{tabular}{|l|r|}
\hline Country/Region & Capacity \\
\hline China & $1,252,214$ \\
\hline Japan & 896,722 \\
\hline Europe \& Middle East & 711,297 \\
\hline SE Asia & 308,419 \\
\hline U.S. & 153,499 \\
\hline S. Korea & 137,175 \\
\hline Taiwan & 104,869 \\
\hline Total & 356,4195 \\
\hline
\end{tabular}

Source: World Fab Forecast. 
Table 10. Optoelectronics wafer capacity

(in 200mm equivalent WPM) by country/region, $2021^{40}$

\begin{tabular}{|l|r|}
\hline Country/Region & Capacity \\
\hline Japan & 657,953 \\
\hline China & 605,938 \\
\hline Taiwan & 296,547 \\
\hline S. Korea & 181,250 \\
\hline U.S. & 150,548 \\
\hline Europe \& Middle East & 60,695 \\
\hline SE Asia & 93,297 \\
\hline Total & $2,046,227$ \\
\hline
\end{tabular}

Source: World Fab Forecast.

Table 11. Sensor wafer capacity

(in 200mm equivalent WPM) by country/region, 2021

\begin{tabular}{|l|r|}
\hline Country/Region & Capacity \\
\hline U.S. & 278,094 \\
\hline China & 105,688 \\
\hline Europe \& Middle East & 129,504 \\
\hline Japan & 170,292 \\
\hline S. Korea & 16,875 \\
\hline SE Asia & 28,150 \\
\hline Taiwan & 7,031 \\
\hline Total & 735,634 \\
\hline
\end{tabular}

Source: World Fab Forecast. 


\section{Appendix C: Offshoring by U.S. semiconductor manufacturers}

American firms, just like non-American firms, must be incentivized to build in the United States. The top U.S.-headquartered firms in logic, memory, and analog increasingly hold most of their wafer capacity overseas. Table 12 below shows that in total, these three firms have less than one third of their overall capacity in the United States, with the remainder in Ireland, Israel, Japan, Singapore, and Taiwan.

Table 12. Most capacity of leading U.S.-headquartered chipmakers is outside of the United States

\begin{tabular}{|c|c|c|c|c|c|c|c|c|}
\hline \multirow[b]{2}{*}{ Company } & \multicolumn{7}{|c|}{ Country } & \multirow[b]{2}{*}{ Total } \\
\hline & China & Ireland & Israel & Japan & Singapore & Taiwan & U.S. & \\
\hline $\begin{array}{l}\text { Analog } \\
\text { Devices }\end{array}$ & & 13 & & & & & 21 & 34 \\
\hline Intel & $120^{41}$ & 148 & 105 & & & & 238 & 611 \\
\hline Micron & & & & 108 & 259 & 313 & 186 & 866 \\
\hline Total & 120 & 161 & 105 & 108 & 259 & 313 & 444 & 1,511 \\
\hline
\end{tabular}

Source: World Fab Forecast. Capacity given in thousands of WPM.

This trend is not entirely attributable to "offshoring." For example, Micron has made many foreign acquisitions in recent years which have likely contributed to its large amount of overseas capacity. Nevertheless, building new fabs in the United States appears to be somewhat rare among these three leading U.S. firms (Figure 4). 
Figure 4. Leading U.S. chipmakers build most new capacity abroad

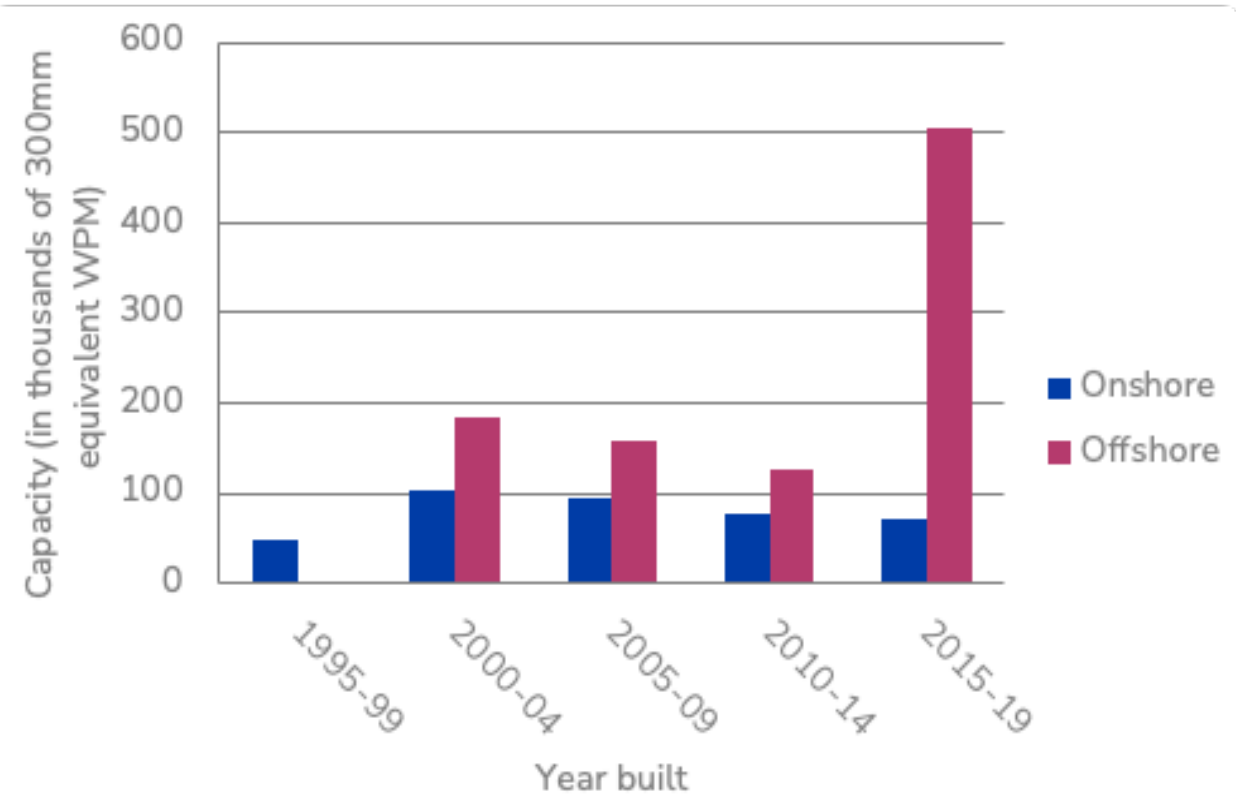

Source: World Fab Forecast.

Note: Y-axis shows total capacity of Analog Devices, Intel, and Micron.

Appendix D: The risks of disruptions in East Asian countries

Taiwan, China, and South Korea have concentrations of manufacturing capacity in logic, memory, and discretes, optoelectronics, and other semiconductors respectively. This section briefly assesses the likelihood of an interruption in supply from each of these three countries. Overall, Taiwan and China face much higher risks of political disruptions than South Korea, due to the potential for an invasion of Taiwan in the coming decade; and Taiwan faces additional risks of natural disruptions. South Korea faces more moderate risks of disruptions, owing primarily to its proximity to North Korea.

\section{Taiwan and China}

Taiwan faces serious risks of both political and natural disruptions. It is located directly on top of a fault line, part of the so-called "Ring 
of Fire" of the Pacific Rim, generating considerable risks of tsunamis and earthquakes, either of which could impact its manufacturing capacity. This is problematic, as fab equipment is highly sensitive to seismic vibrations, and especially violent earthquakes can force fabs to shut down. ${ }^{42}$ The risk is compounded by Taiwan's small size: the island has about the landmass of the state of Maryland. Thus, a natural disaster could put at risk all of Taiwan's fab capacity. There is also precedent for natural disasters disrupting Taiwan's semiconductor industry: in September of 1999, an earthquake forced the Hsinchu Science Park-the center of Taiwan's semiconductor manufacturing - to shut down for six days due to power outages. ${ }^{43}$ Memory-chip prices tripled and shares of electronics companies around the world fell dramatically. ${ }^{44}$ And in 2021, a major drought in the middle of the ongoing global chip shortage forced Taiwan to take emergency measures to secure water for TSMC. ${ }^{45}$

Yet it may be the risk of political disruption in Taiwan that poses the greatest threat of a long-term disruption to Taiwan's manufacturing. An invasion of Taiwan could likely result in a permanent cessation in trade with both China and Taiwan. This would suddenly and dramatically reduce world production of leading-edge (below $7 \mathrm{~nm}$ ) and legacy (above $16 \mathrm{~nm}$ ) logic chips, since Taiwan has roughly 85 percent of leading-edge logic capacity and China and Taiwan together have 65 percent of legacy logic capacity. An invasion would also threaten the 43 percent of global DRAM capacity located in China and Taiwan. It appears unlikely that China would invade Taiwan in order to seize Taiwan's chip manufacturing plants: in such a scenario, Taiwan's plants could be damaged and, more importantly, the United States and its allies could immediately cut off exports of the advanced tools and materials required for chipmaking. Nevertheless, China has long sought to regain possession of Taiwan for other reasons, and the likelihood of an invasion of Taiwan has only risen in recent years.

In the absence of a conflict over Taiwan, it appears unlikely that China would impose controls on legacy logic, DRAM, discretes, or optoelectronics, as these are all commodities with substitutes available from other regions allied with the United States- 
especially Europe and Japan. And the chance of a natural disruption (perhaps from an earthquake) to some of China's capacity is substantial; but the chance of a country-wide loss of manufacturing capacity due to a natural disaster seems remote. China's semiconductor manufacturing capacity is distributed across many cities, none of which contains more than 20 percent of China's total capacity. ${ }^{46}$

\section{South Korea}

South Korea faces limited risks of natural disruptions in manufacturing: the Korean Peninsula is not on the Ring of Fire and has historically seen much less seismic activity than Taiwan or China. Politically, South Korea faces at least two risks. First, a disruption from North Korea could put at risk South Korea's memory capacity, which is clustered in a 100-mile radius around Seoul. ${ }^{47}$ This risk appears to be low but non-negligible. Second, further trade tensions with Japan could also cause interruptions in chipmaking in South Korea. In 2019, Japan imposed controls on exports to South Korea of specialized chemicals required for chipmaking, due to rising tensions between the two countries. Japan subsequently approved export licenses for some photoresists and hydrogen fluoride, reducing tensions. ${ }^{48} \mathrm{We}$ expect that future conflicts will also be resolved through diplomacy: the likelihood of Japan generating a global chip shortage voluntarily seems low, particularly since such a shortage would also hurt Japan.

Appendix E: Costs of reshoring leading-edge logic and DRAM fabs

Table 13 estimates the costs of reshoring leading-edge logic capacity. Initial capital costs and government incentives are based on SIA/BCG analysis. ${ }^{49}$ Costs rise quickly over time due to 5 percent annual growth in global demand and 10 percent annual growth in the capital costs of building new fabs. 
Table 13. Costs of meeting 100 percent of U.S. demand for leading-edge logic

\begin{tabular}{|c|c|c|c|}
\hline Year of production & 2021 & 2023 & 2025 \\
\hline Node (nm) & 5 & 3 & 2 \\
\hline $\begin{array}{l}\text { Capital investment } \\
\text { required per fab } \\
\text { with } 35,000 \text { WPM } \\
\text { capacity }^{50}\end{array}$ & $\$ 20 B$ & $\$ 24 B$ & $\$ 32 B$ \\
\hline $\begin{array}{l}\text { Government } \\
\text { incentives required } \\
\text { per fab } \text { fa }^{51}\end{array}$ & $\$ 4 B$ & $\$ 5 B$ & $\$ 6 \mathrm{~B}$ \\
\hline $\begin{array}{l}\text { Estimated global } \\
\text { demand for } \\
\text { leading-edge } \\
\text { foundry capacity in } \\
\text { WPM }{ }^{52}\end{array}$ & 250,000 & 276,000 & 303,000 \\
\hline $\begin{array}{l}\text { Estimated U.S. } \\
\text { demand in WPM } \\
\text { (1/4 of global } \\
\left.\text { demand }^{53}\right)\end{array}$ & 63,000 & 69,000 & 76,000 \\
\hline $\begin{array}{l}\text { Number of leading- } \\
\text { edge } 35,000 \text { WPM } \\
\text { fabs required to } \\
\text { meet full U.S. } \\
\text { demand }\end{array}$ & 1.8 & 2.0 & 2.2 \\
\hline $\begin{array}{l}\text { Cost of incentives } \\
\text { to meet full U.S. } \\
\text { demand }\end{array}$ & \$7B & $\$ 10 B$ & $\$ 13 B$ \\
\hline
\end{tabular}

Sources: Various — refer to endnotes in the first column. 


\section{Appendix F: Challenges with the Trusted Foundry Program}

The DOD adopted the Trusted Foundry Program in 2004. Under the program, the government would pay semiconductor companies based in the United States for guaranteed access to secure chips. In 2007, the program expanded to include other parts of the supply chain, including design and assembly, test, and packaging. The focus of the program was security, and to be eligible suppliers were required to gain security clearances for employees manufacturing any sensitive products. ${ }^{54}$

The problem with this approach—now widely acknowledged-is at least threefold. First, the government is not a major purchaser of microelectronics, so chipmakers building "trusted" chips for the government, such as GlobalFoundries, do not have the incentive to innovate to the degree that commercially-focused foundries like TSMC do. Partly as a result, foundries focused on supplying the DOD have tended to fall behind the leading edge, forcing the military to use outdated chips. Second, semiconductor supply chains are global and highly complex. It is difficult to establish the security of suppliers across the entire supply chain, despite efforts to expand the supplier accreditation program. Third, there is always a risk of a trusted individual working inside a secure facility taking actions that compromise security.

In part as a result of the weaknesses of the Trusted Foundry Program, sensitive parts of the U.S. computing infrastructure rely on chips that are not made in the United States. To give just one example, DOE supercomputers currently listed on the TOP500 use Nvidia chips (in addition to chips from IBM and Intel) which are made by TSMC in Taiwan..$^{55} \mathrm{~A}$ National Defense Industrial Association white paper notes that "The absence of DMEAaccredited Trusted Foundries at advanced semiconductor process nodes has the potential to precipitate a crisis for DoD. Unmitigated, this crisis could disadvantage DoD with asymmetric semiconductor capabilities and/or undermine DoD Instruction 5200.44 requirements to use Trusted Suppliers for military end use semiconductors, resulting in increasingly frequent waivers of those 
requirements. ${ }^{56}$ Further highlighting this challenge, DOE chose Intel to supply advanced logic chips used in an upcoming supercomputer-only to see delays at Intel which impacted upgrades to DOE's network of high-performance computers. ${ }^{57}$

Because of the challenges associated with the Trusted Foundry Program, the DOD has begun to move toward a "zero-trust" approach to microelectronics purchases, where chips are assumed not to be safe until proven otherwise through extensive testing. ${ }^{58}$ However, this transition is still in its early stages. 


\section{Endnotes}

${ }^{1}$ While the CHIPS Act has authorized spending, the necessary funding has not yet been appropriated, though it appears likely to be appropriated eventually. Steven Overly, "Frustration builds over stalled China competition bill," Politico, October 25, 2021, https://www.politico.com/newsletters/weeklytrade/2021/10/25/frustration-builds-over-stalled-china-competition-bill798425 .

${ }^{2}$ An exception is advanced analog chips, which are often customized for specific use cases and are especially important for military and other sensitive applications. The United States already has considerable analog capacity onshore, and projected gaps in capacity could be targeted with the $\$ 2$ billion in CHIPS incentives earmarked for legacy chip manufacturing; and analyzing future trends in advanced analog supply and demand, and potential future gaps in U.S. analog onshore capacity, is beyond the scope of this paper.

${ }^{3}$ See forthcoming CSET research on advanced packaging supply chains and U.S. talent needs generated by CHIPS Act funding and John VerWey, "No Permits, No Fabs: The Importance of Regulatory Reform for Semiconductor Manufacturing" (Center for Security and Emerging Technology, October 2021), https://cset.georgetown.edu/publication/no-permits-no-fabs/.

${ }^{4}$ Krugman, Paul. "Increasing returns and economic geography." Journal of Political Economy 99, no. 3 (1991): 483-499.

${ }^{5}$ While the CHIPS Act has authorized spending, the necessary funding has not yet been appropriated, though it appears likely to be appropriated eventually. Overly, "Frustration builds over stalled China competition bill."

${ }^{6}$ Note that all of these estimates are approximate and would change considerably depending on the type of capacity targeted with incentives. Estimates also exclude capacity below 8" and capacity at fabs with less than 5,000 wafers per month (WPM). Antonio Varas et al., "Government Incentives and US Competitiveness in Semiconductor Manufacturing" (Boston Consulting Group and Semiconductor Industry Association, 2020), https://www.semiconductors.org/wp-content/uploads/2020/09/GovernmentIncentives-and-US-Competitiveness-in-Semiconductor-Manufacturing-Sep2020.pdf.

${ }^{7}$ For details on how applications were sorted into sensitive vs. non-sensitive, see Appendix A, Table 4.

${ }^{8}$ See Appendix B for a detailed breakdown of capacity across countries and devices. 
${ }^{9}$ Note that if our definition of leading-edge is expanded to include Intel's most advanced logic chips (which are roughly one generation behind TSMC and Samsung's $5 \mathrm{~nm}$ chips), then U.S. capacity increases greatly.

${ }^{10}$ Fabs often do not specialize exclusively in optoelectronics, making classification of fabs in SEMI World Fab Forecast data difficult. One non-public estimate suggests that 44 percent is an overestimate of these countries' share of global optoelectronics capacity.

${ }^{11}$ A different approach to countering China's subsidies is to consider challenging those subsidies at the World Trade Organization. However, such a challenge could take years to resolve and may not succeed if there is insufficient evidence to prove that other countries' subsidies are illegal under WTO rules. Moreover, the United States is now itself incentivizing fab construction with CHIPS Act funding, so challenging similar subsidies under the WTO could backfire.

12 "How to Spend \$39 Billion," Semi-Literate, June 13, 2021, https://semiliterate.substack.com/p/how-to-spend-39-billion.

${ }^{13}$ For a more detailed analysis of demand, cost, and required incentives, see Appendix E. Note that $5 \mathrm{~nm}$ logic capacity will have fallen behind the leading edge by the time it has been constructed. Note that $5 \mathrm{~nm}$ capacity already is already under construction by TSMC (David Manners, "TSMC said to be planning \$35bn Arizona Gigafab," ElectronicsWeekly.com, March 15, 2021, https://www.electronicsweekly.com/news/business/tsmc-reported-planninga35bn-gigafab-arizona-2021-03/) and perhaps by Samsung as well (Omar Sohail, "Samsung Reportedly Close to Finalizing Its \$17 Billion Chip Plant in Texas in an Effort to Catch up to TSMC," Wccftech, September 29, 2021, https://wccftech.com/samsung-close-to-finalizing-17-billion-texas-chip-facility/), likely due to federal incentives which may have already been informally committed by the USG.

${ }^{14}$ Fab capacity is generally denominated in "wafers per month" or "wafer starts per month." This simply describes the number of wafers that go through the production process per month. Note that wafer starts do not equate with finished wafers: some wafers have problems, resulting in a less than 100 percent "yield."

${ }^{15}$ Adding capacity to meet full U.S. demand at the $1.5 \mathrm{~nm}$ (projected leadingedge in 2028) node, could require more than $\$ 21$ billion in additional funding more than half of the funding expected to be appropriated for CHIPS Act manufacturing incentives. Thus, if further incentives are needed later in the decade, it may be necessary to appropriate additional funding. An additional alternative could involve meeting a smaller fraction of U.S. demand for leadingedge logic, in order to allow manufacturing incentives to last longer. However, 
reducing the amount of capacity incentivized will increase costs per wafer to chipmakers and to the U.S. government, given the significant economies of scale involved in chip production. Meeting just one-third of U.S. demand over 10 years would cost approximately as much as meeting 100 percent over five years.

${ }^{16}$ Samsung and TSMC should be incentivized to build at the leading edge both firms are currently developing the $3 \mathrm{~nm}$ node, which should be ready for commercial production in 2023. Leo Sun, "Will Intel's 'Accelerated' Chipmaking Plans Spell Trouble for TSMC?," The Motley Fool, August 3, 2021, https://www.fool.com/investing/2021/08/03/will-intel-accelerated-chipmakingplans-spell-tsmc/. Intel is currently unable to manufacture chips competitive with TSMC and Samsung's $3 \mathrm{~nm}$ and $5 \mathrm{~nm}$ nodes.

${ }^{17}$ Intel's estimates of U.S. consumption of Intel chips are somewhat higher than CSET's estimates. However, these differences are not enough to change our conclusion that Intel should receive incentives to support one leading-edge fab rather than two. Offering two leading-edge fabs to Intel and one each to Samsung and TSMC would result in the U.S. depending on Taiwan for 50 percent of its consumption of TSMC-manufactured chips. This level of dependence is risky given the significant chance of disruptions in Taiwan over the coming decade.

${ }^{18}$ Apple and Samsung together enjoy roughly 77 percent of the U.S. smartphone market, which ships approximately 140 million smartphones per year in the United States (S. O'Dea, "Number of smartphone unit shipments in the United States from 2013 to 2025," Statista, October 15, 2021, https://wwwstatista-com.proxy.library.georgetown.edu/statistics/619811/smartphone-unitshipments-in-the-us/); S. O'Dea, “Manufacturers' market share of smartphone sales in the United States from $1^{\text {st }}$ quarter 2016 to $2^{\text {nd }}$ quarter 2021," Statista, November 22, 2021, https://www-statistacom.proxy.library.georgetown.edu/statistics/620805/smartphone-sales-marketshare-in-the-us-by-vendorl. We exclude from this analysis the 35 million smartphones shipped by companies other than Apple and Samsung, as it is difficult to determine which chipmakers manufactured the chips in this portion of the market.

${ }^{19}$ Total is based on the average units projected to be shipped per year between 2021 and 2025 (Lionel Sujay Vailshery, "Unit shipments of tablets in the United States from 2015 to 2025," Statista, October 15, 2021, https://www.statista.com/statistics/619369/tablet-unit-shipments-in-the-us/). Breakdown between TSMC and Samsung is based on the assumption that all of Apple's 56 percent in September of 2021 is based on TSMC chips, while tablets from Samsung based on the Android operating system comprise the remainder. Shanhong Liu, "Tablet operating systems market share in the United States from 2016 to 2021," Statista, October 4, 2021, https://www-statista- 
com.proxy.library.georgetown.edu/statistics/271293/market-share-held-bytablet-os-us/. This may somewhat overestimate the number of Samsung chips.

${ }^{20}$ Total is based on aggregating the following figures, and then rounding to avoid false precision. 68 million laptops and 18 million gaming consoles are projected to be sold in the United States in 2021 (Lionel Sujay Vailshery, "Forecast volume of consumer electronics in the U.S. for 2021, by selected product," Statista, February 5, 2021, https://www-statistacom.proxy.library.georgetown.edu/statistics/1198270/ce-industry-shipments2021-by-product/). Add to this an estimated 20 million desktop PCs (roughly $1 / 5$ of total annual desktop PC shipments) (Thomas Alsop, "Notebook, desktop PC, and tablet shipments worldwide from 2010 to 2025," Statista, November 23,

2021, https://www-statista-

com.proxy.library.georgetown.edu/statistics/272595/global-shipments-forecastfor-tablets-laptops-and-desktop-pcs/). Servers, though a significant source of revenue given their high price per unit, account for just 12 million global shipments globally, of which perhaps 25 percent ( 3 million) are shipped to the United States (Thomas Alsop, "Server shipments worldwide from 2010 to 2020," Statista, April 8, 2021, https://www-statistacom.proxy.library.georgetown.edu/statistics/219596/worldwide-servershipments-by-vendor/). Most of these devices are based on the x86 instruction set architecture (ISA), and Intel generally has roughly 60 percent market share on all $x 86$ devices, with the remainder coming from AMD (which uses TSMC as its chipmaker) (Thomas Alsop, "Distribution of Intel and AMD x86 computer central processing units (CPUs) worldwide from 2012 to 2021, by quarter," Statista, October 28, 2021, https://www.statista.com/statistics/735904/worldwide-x86-intel-amd-marketshare/). Note that Apple also holds 15 percent of the market for personal computers in the United States; it uses the ARM ISA and TSMC as a manufacturer. Samsung chips do not appear to be a large part of this market (Thomas Alsop, "Personal computer (PCs) shipment share in the United States from 2013 to 2021, by quarter," Statista, November 1, 2021, https://wwwstatista-com.proxy.library.georgetown.edu/statistics/816458/shipment-sharepcs-united-states-vendor//). Our overall estimate is that between Apple and AMD, TSMC currently manufactures 45 percent of leading-edge microprocessors shipped in the United States.

${ }^{21}$ Manners, "TSMC said to be planning \$35bn Arizona Gigafab"; "Intel Breaks Ground On Two New Semiconductor Factories," Office of the Governor Doug Ducey, September 24, 2021, https://azgovernor.gov/governor/news/2021/09/intel-breaks-ground-two-newsemiconductor-factories; William Kim, "Samsung to Build Advanced Chip Factory in Texas," Texas Signal, September 10, 2021, https://texassignal.com/samsung-to-build-chip-factory-in-texas/. All of these plans appear to be contingent on receiving CHIPS Act funding. For example, see 
Intel's threat to scuttle its new fabs if funding for the CHIPS Act is not approved. Daniel Flatley, "Intel Rethinking Chips Investment as Congress Dithers on Funding," BNN Bloomberg, October 22, 2021, https://www.bnnbloomberg.ca/intel-rethinking-chips-investment-as-congressdithers-on-funding-1.1670235.

22 Note that the costs of meeting full leading-edge demand are rising exponentially. For example, meeting full U.S. demand at the $1.5 \mathrm{~nm}$ node would require roughly $\$ 20$ billion in incentives according to CSET calculations.

${ }^{23}$ See Table 11 in Appendix C.

${ }^{24}$ See Figure 4 in Appendix C.

${ }^{25}$ The Semiconductor Industry Association estimates that the capital costs required for a 100,000 WPM NAND flash fab amount to roughly \$20 billionthe same as the cost of a 35,000 WPM advanced logic fab. If we assume that flash and DRAM fabs require similar proportions of government incentives to total capital investments, this would imply that it takes $\$ 4$ billion to incentivize a DRAM fab. However, DRAM fabs typically require more sophisticated equipment than NAND flash fabs (and equipment is a major cost driver). Thus, we shade this estimate upward to \$5-10 billion. The only non-public estimate we have seen for the incentives required for one leading-edge DRAM fab falls into this range.

${ }^{26}$ The investments recommended here focus on the leading-edge chips of today, used for smartphones, personal computers, servers, autonomous driving, and other applications requiring the most sophisticated processors. But as semiconductor technologies continue to advance forward every two to three years, today's leading-edge capacity will eventually fall behind, and will come to be used by a range of other critical U.S. industries that depend on less expensive legacy chips. Indeed, the current chip shortage is centered on legacy chip capacity, some of which was originally built two decades ago to meet the needs of leading-edge computers at that time. Agam Shah, "Chip manufacturers are going back to the future for automotive silicon," The Register, October 19, 2021, https://www.theregister.com/2021/10/19/chip_manufacturer_chips/.

${ }^{27}$ Indeed, shortages of these inexpensive chips have largely driven the problems facing the auto industry over the course of 2020. Jack Ewing and Neal E. Boudette, "A Tiny Part's Big Ripple: Global Chip Shortage Hobbles the Auto Industry," The New York Times, April 23, 2021, https://www.nytimes.com/2021/04/23/business/auto-semiconductors-generalmotors-mercedes.html. 
${ }^{28}$ As an example, a comment on the recent BIS request for information on supply chain vulnerabilities notes that the United States may cease to have 32 $\mathrm{nm}$ logic capacity within a few years: "After GF-2 closes their $32 \mathrm{~nm}$ line in Dec 2021 only Intel's $32 \mathrm{~nm}$ line will be available in the U.S. This line is 11 years old and probably only has several years left before end of life. Again, $\mathrm{HSSi}$ recommends U.S. government approach Intel to purchase this production line and process for salvage value. The U.S. Government could then provide the tooling to another U.S. based firm as Government Furnished Equipment (GFE) and allow legacy node microchips to be fabricated onshore."

29 Previous CSET analysis shows that the capital costs associated with fab construction and equipment rise about 11 percent per year (Saif M. Khan, "Al Chips: What They Are and Why They Matter" [Center for Security and Emerging Technology, April 2020], https://cset.georgetown.edu/publication/ai-chips-whatthey-are-and-why-they-matter/). Thus, building new legacy capacity at, e.g., the $22 \mathrm{~nm}$ node- which first reached commercial production by Intel in 2012should be less than half the cost of leading-edge $5 \mathrm{~nm}$ logic fabs in 2020 (11 percent compound annual growth over 8 years yields a 2.3X cost increase). Assuming the required government incentives are proportional to capital costs, this suggests incentives per $22 \mathrm{~nm}$ fab should be less than half the estimated $\$ 4$ billion incentives required for each $5 \mathrm{~nm}$ logic fab. This suggests a cost of roughly $\$ 1.7$ billion per $22 \mathrm{~nm}$ fab, and somewhat lower costs for each $32 \mathrm{~nm}$ fab. Thus with \$4-9 billion in incentives, we estimate the United States could build anywhere from 2-5 legacy logic fabs.

${ }^{30}$ A different approach to counter China's subsidies is to consider challenging those subsidies at the World Trade Organization. However, such a challenge could take years to resolve and may not succeed if there is insufficient evidence to prove that other countries' subsidies are illegal under WTO rules. Moreover, the United States is now itself incentivizing fab construction with CHIPS Act funding, so challenging similar subsidies under the WTO could backfire.

${ }^{31}$ The following applications were coded by CSET as high-sensitivity:

Automotive, Military/Civil Aerospace Electronics, Mobile Infrastructure - Base Station Equipment, Medical/Healthcare, Security, Server, 1 CPU Socket, Server, 4 CPU Socket, Server, 2 CPU Socket, and Wireless LAN Infrastructure. All other applications were coded as low-sensitivity. Note that the market for servers makes up a large portion of "high-sensitivity" sales, and many servers (for example, those offering cloud services for video games) may have relatively lowsensitivity applications, perhaps resulting in an overestimate of the total value of truly high-sensitivity sales. The most sensitive applications, such as government and military applications, make up a much smaller fraction of the market. 
${ }^{32}$ Varas et al., "Government Incentives and US Competitiveness in Semiconductor Manufacturing."

${ }^{33}$ Gartner Inc., Semiconductor Forecast Database, Worldwide, 1Q21 Update TM, Ben Lee et al., March 30, 2021, https://www.gartner.com/en/documents/3999992/gartner-marketdatabook1q21-update.

${ }^{34}$ Note that this is not the same as consumer demand for finished electronic devices. Our model of U.S. consumer demand for logic chips in Appendix E is based on SIA estimates which use other proprietary datasets, rather than EndUse Report data.

${ }^{35}$ Note that SIA's end-use data only tracks where finished chips are shipped, and does not assess where chips are re-exported after being incorporated into larger electronic devices.

${ }^{36}$ Consumption in North and South America is almost entirely attributable to the United States.

${ }^{37}$ The research group IMEC has 10,000 wafers per month-WPM-in capacity at $5 \mathrm{~nm}$, but IMEC is not a commercial supplier of chips.

${ }^{38}$ Wafers come in different sizes: $200 \mathrm{~mm}$ wafers are common for legacy commercial chips, while all leading-edge logic and memory chips are made with $300 \mathrm{~mm}$ wafers. To convert between $200 \mathrm{~mm}$ and $300 \mathrm{~mm}$ capacity, divide figures given in the tables by 2.25 .

${ }^{39}$ Micron and Intel have a limited amount of 3D XPoint capacity within the United States. 3D XPoint is non-volatile, like NAND flash, but faster-and more expensive - like DRAM. But this capacity is limited and declining: Micron announced in March that it would sell its only 3D XPoint fab. Carol Sliwa, "Intel breaks silence on effects of Micron's 3D XPoint exit," TechTarget, April 22, 2021, https://searchstorage.techtarget.com/news/252499716/Intel-breaks-silence-oneffects-of-Microns-3D-XPoint-exit.

40 Fabs often do not specialize exclusively in optoelectronics, making classification of fabs in SEMI World Fab Forecast data difficult. China and Taiwan are generally considered to be relatively minor players in the optoelectronics industry, so this figure may be overestimating their share of global optoelectronics capacity.

${ }^{41}$ This represents capacity from Intel which will soon be divested. Hyunjoo Jin and Stephen Nellis, "South Korea's SK Hynix to buy Intel's NAND business for $\$ 9$ billion," Reuters, October 19, 2020, https://www.reuters.com/article/us-intel- 
divestiture-sk-hynix/south-koreas-sk-hynix-to-buy-intels-nand-business-for-9billion-idUSKBN2742IY.

${ }^{42}$ Indeed, seismic isolation can be one of the more time-intensive and expensive parts of the fab construction process. Katherine Derbyshire, "Building a Fab - It's All About Tradeoffs," Semiconductor Magazine (June 2002), https://www.dpr.com/assets/news/2002-06-01-semiconducotr-mag.pdf.

${ }^{43}$ Antonio Varas, Raj Varadarajan, Jimmy Goodrich, Falan Yinug, "Strengthening the Global Semiconductor Supply Chain in an Uncertain Era" (Boston Consulting Group and Semiconductor Industry Association, April 2021), https://www.semiconductors.org/wp-content/uploads/2021/05/BCG-x-SIAStrengthening-the-Global-Semiconductor-Value-Chain-April-2021_1.pdf.

${ }^{44}$ Varas et al., "Strengthening the Global Semiconductor Supply Chain in an Uncertain Era."

${ }^{45}$ Chip fabrication requires large volumes of water. Stephanie Yang, "The Chip Shortage Is Bad. Taiwan's Drought Threatens to Make It Worse," The Wall Street Journal, April 16, 2021, https://www.wsj.com/articles/the-chip-shortageis-bad-taiwans-drought-threatens-to-make-it-worse-11618565400.

${ }^{46}$ Lee et al., "Semiconductor Forecast Database, Worldwide, 1Q21 Update."

${ }^{47}$ Forty-one percent of South Korea's NAND flash capacity is in the city of Cheongju, while 51 percent of its DRAM capacity is in Hwaseong. Lee et al., "Semiconductor Forecast Database, Worldwide, 1Q21 Update."

${ }^{48}$ Samuel Goodman, John VerWey, Dan Kim, The South Korea-Japan Trade Dispute in Context: Semiconductor Manufacturing, Chemicals, and Concentrated Supply Chains (Washington, DC: Office of Industries, International Trade Commission), https://papers.ssrn.com/sol3/papers.cfm?abstract_id=3470271.

${ }^{49}$ Varas et al., "Strengthening the Global Semiconductor Supply Chain in an Uncertain Era."

${ }^{50}$ Based on SIA/BCG estimates for a $5 \mathrm{~nm}$ advanced logic fab. Varas et al., "Strengthening the Global Semiconductor Supply Chain in an Uncertain Era."

51 Inferred from SIA/BCG estimates. Varas et al., "Strengthening the Global Semiconductor Supply Chain in an Uncertain Era."

52 Data from VLSI Research suggests that TSMC built roughly 250,000 WPM in new leading edge capacity over four years (2018-2021), equally distributed across the 5 and $7 \mathrm{~nm}$ nodes. We assume that TSMC produces half of leading- 
edge chips, and thus meeting global demand for leading-edge capacity requires building 250,000 WPM in new capacity every two years in 2021. We expect global demand to increase at a rate of 5 percent per year, following the semiconductor industry as a whole. "Worldwide Semiconductor Revenue Grew 5.4\% in 2020 Despite COVID-19 and Further Growth Is Forecast in 2021, According to IDC," BusinessWire, February 2, 2021, https://www.businesswire.com/news/home/20210202005299/en/WorldwideSemiconductor-Revenue-Grew-5.4-in-2020-Despite-COVID-19-and-FurtherGrowth-Is-Forecast-in-2021-According-to-IDC.

53 The assumption that the United States consumes one-fourth of all leadingedge chips is based on SIA and BCG's estimate that the United States consumes one-fourth of all chips; in the absence of better data, we assume this holds true for leading-edge logic (Varas et al., "Strengthening the Global Semiconductor Supply Chain in an Uncertain Era."). This could be an overestimate or an underestimate. On the one hand, SIA and BCG's estimates are given in terms of sales revenue rather than wafers; this will tend to bias the results upward, as the United States likely consumes more expensive chips than the rest of the world on average. On the other hand, SIA and BCG assess U.S. consumption across all devices and nodes, whereas the analysis in this paper focuses on only leadingedge logic, which are likely consumed more heavily in the United States. This would tend to bias the results downward.

54 Michaela D. Platzer, John F. Sargent Jr., and Karen M. Sutter, "Semiconductors: U.S. Industry, Global Competition, and Federal Policy” (Congressional Research Service, October 26, 2020), https://crsreports.congress.gov/product/pdf/R/R46581.

55 See for example the Summit supercomputer ("June 2021," Top500, https://www.top500.org/lists/top500/2021/06/). Using TSMC chips likely required a waiver.

${ }^{56}$ John Robert Adams et al., "Team 4 White Paper: New Methods to Instill Trust in Commercial Semiconductor Fabrications” (NDIA, July 2017), https://www.ndia.org/-/media/sites/ndia/divisions/working-groups/tmjwgdocuments/ndia-tm-jwg-team-4-white-paper-finalv3.ashx.

57 Don Clark, "Intel Slips, and a High-Profile Supercomputer is Delayed," The New York Times, August 27, 2020, https://www.nytimes.com/2020/08/27/technology/intel-aurorasupercomputer.html.

58 Jackson Barnett, “Zero trust gains momentum as DOD's new approach to manage microelectronics acquisition," Fedscoop, May 28, 2020, https://www.fedscoop.com/zero-trust-gains-momentum-dods-techacqusistions/. 